\title{
Women's Health and Wellness
}

\section{Development of In Vitro Fertilization, a Very Important Part of Human Reproductive Medicine, in the Last 40 Years}

\author{
Marte Myhre Reigstad ${ }^{*}$ and Ritsa Storeng
}

Norwegian Advisory Unit on Women's Health, Oslo University Hospital, Norway

*Corresponding author: Marte Myhre Reigstad, Norwegian Advisory Unit on Women's Health, Oslo University Hospital, Oslo, Norway, Tel: +4799002294, Fax +47-23-07-26-84

\begin{abstract}
It is estimated that, worldwide, over 8 million babies are born following infertility treatment with in vitro fertilization (IVF) since the birth of world's first IVF baby 40 years ago. Recent estimates suggest that by year 2100, 400 million individuals or $3 \%$ of the world population may be alive as a result of IVF and other fertility treatments. The developments within infertility treatment using techniques and procedures that evolved from initially animal and lately human research are enormous. Some of the technological advances in reproductive medicine have also contributed to developments and treatment possibilities in other fields of medicine. This mini review article aims to briefly describe and summarize the developments seen in this fascinating field of medicine over the past 40 years.
\end{abstract}

\section{Keywords}

Infertility, Reproductive medicine, In vitro fertilization, Prenatal diagnosis, Womens' health issues, Physiology of reproduction

\section{Introduction}

In January 2018 the UK government opened up for three-parent conception, with the legalization of donation of mitochondrial DNA in cases where genetic disease may be transmitted to the offspring through affected maternal mitochondrial DNA [1]. This happened 40 years after the birth of the world's first test tube baby, Louise Brown [2]. In 2018 The International Committee Monitoring Assisted Reproductive Technologies (ICMART's) reported from its annual collection of global in vitro fertilization (IVF) data, that an estimated 8 million babies are born worldwide from IVF This has been a novel treatment method and concerns have been raised as to the health both of treated women, but also as to the health of their offspring. However, the health of these women and their offspring has not indicated any major concerns [3].

The technological developments in the IVF field have been beyond imagination during the last four decades, such as cryopreservation of surplus embryos [4], the introduction of intracytoplasmic sperm injection (ICSI) to treat male factor infertility [5], chromosomal screening by preimplantation genetic diagnosis (PGD) [6], mitochondrial donation or three parent IVF [1], cryopreservation of ovarian tissue [7] uterine transplantation [8] and many other modification in the treatment of infertility that would not be possible without IVF. Something that has also forced politicians, researchers and health policy makers to take ethical considerations and make difficult decisions; as possibilities that previously were seen as unrealistic and impossible, actually became a reality. An example of this is the discussion of donation of surplus embryos (known as "snowflake adoption"), and oocyte donation.

This mini review aims to summarize the development of in vitro fertilization techniques and clinical applications over the past 40 years. Figure 1 displays a timeline of some of the events during this time span.

\section{Increasing Prevalence of Infertility}

A substantial proportion of couples currently delay childbearing in order to pursue other life goals first. The cost of such delay may be reduced fecundity, in large part reflecting the observed elevated incidence

Citation: Reigstad MM, Storeng R (2019) Development of In Vitro Fertilization, a Very Important Part of Human Reproductive Medicine, in the Last 40 Years. Int J Womens Health Wellness 5:089. doi. org/10.23937/2474-1353/1510089 


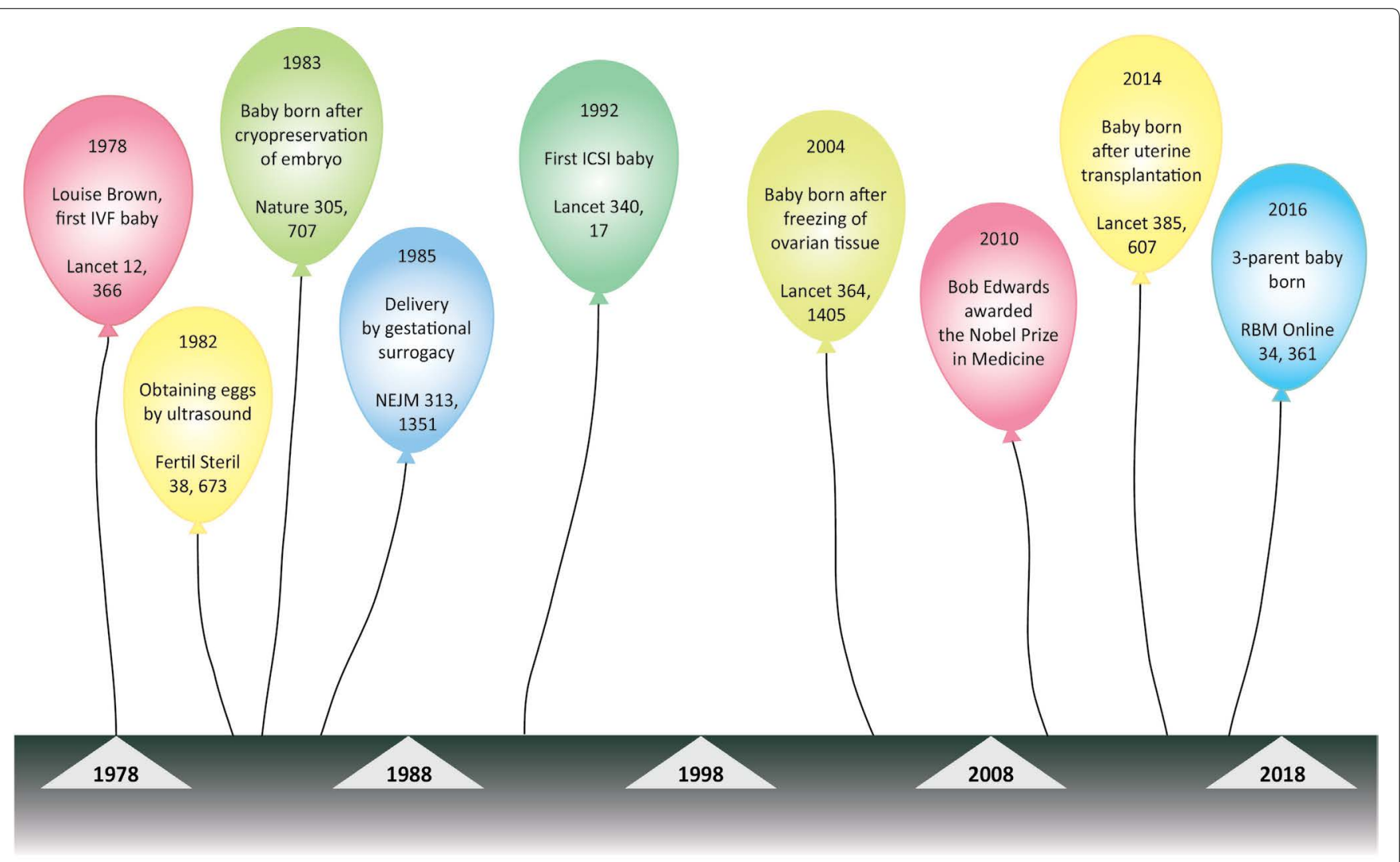

Figure 1: Timeline figure of important events during the 40 years of in vitro fertilisation (IVF).

of infertility in recent years [9]. Infertility is defined as the failure to achieve a clinical pregnancy after 12 months or more of regular unprotected sexual intercourse and the prevalence is reported to lie between 10 and $15 \%$ of all couples [10]. The most important cause of female infertility is age, primarily through age related decline in ovarian reserve [11]. Other common causes of female infertility are ovulatory disorders, tubal factors, endometriosis, cervical factors and unexplained infertility [12]. Male factor infertility comprises approximately $30 \%$ of cases, and contributes to $50 \%$ of cases overall [13]. Common causes of male infertility are sperm production issues, genetic factors and ejaculation dysfunctions, lifestyle factors (smoking, alcohol and drug use) as well as environmental factors such as working with pesticides.

\section{Early Day Assisted Reproduction}

Although we are celebrating 40 years of human IVF, the techniques involved have been around much longer and are still evolving. In the United States in the 1930s G. Pincus and E.V. Enzmann from Harvard University made the first attempts at mammalian IVF in mice models [14]. Their work much involved understanding how hormones played a role in reproductive processes, and in 1934 they published an article claiming they had performed IVF in a rabbit [15]. During the next decade two researchers, M. Menken and J. Rock tried to achieve clinical IVF and observed cleavage of human zygotes in vitro, as reported in the American Journal of Obstetrics and Gynecology [16]. Shortly after this, Menken reportedly left Harvard, and when she returned some years later, Rock had left the field of in vitro fertilization, and had, ironically, moved on to work on the development of the contraceptive pill.

A further decade later the first successful mammalian birth following in vitro fertilization in the rabbit was reported by Bedford and Chang in 1962 [17]. Chang however, was more interested in the scientific value of this achievement, and not its clinical application, as he pointed out "there were too many people in the world already".

A few years later, based on his expertise in animal reproductive physiology, Robert Edwards suggested that by priming doses of follicular stimulating hormone it should be possible to obtain more oocytes, thus initiating the idea of modern ovarian stimulation and ultimately the growth and in vitro fertilization of human oocytes [18].

Before the successful birth in 1978 of Louise Brown at Oldham Hospital, R. Edwards and his team at Bourn Hall had made over 100 attempts at transferring the in vitro produced embryo. However, no pregnancy progressed further than what we today know as a biochemical pregnancy. The reasons for this are thought to be that the injected hormones created harsh intrauterine environment. By abandoning hormone stimulation and using only monitoring of the natural cycle by measuring the concentration of luteinizing hormone in the woman's urine, the intrauterine conditions for a successful pregnancy became more favorable and subsequently it happened, the birth of Louise Brown, a result of IVF in a natural cycle [2]. 


\section{Bob Edwards and Baby Louise Joy Brown}

The work by Edwards, Steptoe and Purdy at the Dr. Kershaw's Cottage Hospital in the years leading up to this birth, has been named "among the towering achievements of recent British biology". During the following years, Robert Edwards and his team assisted the conception of more than 1000 babies, at that time comprising more than half of all IVF babies worldwide [19]. Alongside him had worked the gynaecologist Patrick Steptoe and the nurse and embryologist, Jean Purdy. She was a cofounder of the Bourn Hall clinic, and performed the actual insemination in vitro and the first to see the embryo that resulted in Louise Brown's birth. Edwards was in 2010 awarded the Nobel prize in Physiology and Medicine for this work [20]. Since the first birth, the demand and supply of fertility treatments has exploded, and large economical and commercial interests have become involved in this field of medicine. For example the UK fertility market is worth ca 340 million euros (320 million pounds) and experiencing accelerating growth [21]. The success rate has also improved, and today approximately $60-70 \%$ of couples treated for infertility end up with a healthy child [22].

\section{Advancements in the Early Treatments}

Not surprisingly, many scientists working with infertile patients all around the world, were intrigued by this new field of medicine and "the enthusiasm was contagious", as stated by Jean Cohen. Cohen, alongside Jaqueline Mandelbaum and Michelle Plachot were the French IVF pioneers [23]. There were also fears and skepticism among the same people, and in many clinics, such as at the Monash University in Australia, it was commonplace to perform amniocentesis on all IVF pregnancies. Ironically, the first pregnancy after IVF in Australia resulted in a second trimester miscarriage following such a procedure [24]. The tedious work in reproductive centers in Australia, the UK, the US and the Nordic countries have contributed many small steps, which have proved important in the development of modern day IVF. The first trials of IVF were made with ovarian stimulation by the anti-estrogen clomiphene citrate. Drs. Georgeanna S. and Howard W. Jones announced the first US born IVF baby in 1981, [25] and they had, for the first time, used human menopausal gonadotropin (hMG) for controlled ovarian hyperstimulation. Further, in 1982 R. Fleming demonstrated that stimulation with $\mathrm{GnRH}$ (Gonadotropin releasing hormone) agonists could reduce the premature ovulation induced by endogenous LH surge [26]. Improvements in the treatment protocols in the early 90ies, induced more mature follicles per stimulation cycle and more oocytes were aspirated. This not only increased the chances of conception for infertile couples, but also precipitated a need for a suitable cryopreservation and storage procedures for the surplus embryos. This work was fronted by the Australian Alan Trounson and his team, at the Monash Institute in Melbourne and the group reported the first birth after cryopreservation of an embryo in 1983 [4].

Another significant achievement was intracytoplasmic sperm injection (ICSI) in the early 1990ies. Inserting a single sperm cell into the ovum, left improved treatment outcomes for couples suffering from male factor infertility and in Belgium in 1992 the world's first "ICSI baby" saw the light of day [5].

In the clinical setting, vaginal ultrasound technology paralleled the aforementioned developments. Already in the mid-eighties, follicle development monitoring, individual dose adjustment of hormone stimulation protocols and oocyte aspiration were done by ultrasound guidance [27], a procedure developed in Scandinavia by the Swedish gynecologists Matts Wikland and Lars Hamberger [28]. Prior to this, follicle aspiration was performed under general anesthesia by percutaneous aspiration.

Improvements in the scientific part of the treatment, i.e. the in vitro culture techniques, laboratory standards such as air quality, temperature in incubators, culture media composition and standardization as well as improvements in embryo development monitoring have also contributed in the establishment of the successful IVF-treatment. The initial introduction of elective single embryo transfer in the Nordic countries and its adoption by other countries has contributed greatly in reducing the incidence of and the risks associated with multiple births [29].

\section{IVF - A developing Field; Oocyte Donation, Preimplantation Genetic Diagnosis and Study of Early Human Development}

Following the first pregnancy after donation of an egg [30], the possibility of treating women with premature ovarian failure became an option. Three parent babies [1] and babies born after uterine transplantations in women born without a uterus are also among the most cutting edge treatments [8]. The possibility of preimplantation genetic diagnosis (PGD) and screening (PGS), were also made possible as a direct result of IVF [6]. It has enabled preimplantation genetic testing (PGT) of embryos before embryo transfer, enabling the transfer of genetically normal embryos. Studying the development of early human embryos has been made possible by IVF. Superfluous embryos created by IVF and donated by the parents are now being used in the laboratory to study key early processes, such as implantation, involved in the shaping of the embryo and its supporting tissues. These studies are, however, strictly regulated by the "14-day rule" which does not allow research on human embryos to fourteen days after fertilization [31].

\section{Future Perspectives}

The use of IVF has increased in recent years, mostly due to delayed childbearing, and there is little reason to 
Table 1: Current antifertility treatments for women and men - advantages and disadvantages.

Mode of treatment
Artificial insemination
IVF With egg donation
ICSI for male factor infertility
TESA, PESA to obtain sperm

believe that this trend will halt. In fact, recent estimates suggest that by year 2100,400 million individuals or $3 \%$ of the world population may be alive as a result of assisted reproductive technologies (ART) [32]. Underlying this prediction is an assumption that the use of IVF will rise even more in middle and low-income countries in years to come. The efficiency and safety of treatments are therefore of paramount importance. Future challenges remain for IVF research in the future. The big questions are how to overcome the inevitable problem of oocyte ageing and female infertility, understanding and thereby developing measures to overcome implantation issues, as well as working for treatments for male infertility. Only the future will show what possibilities the next 40 years will bring for assisted reproduction, with such strong driving forces among the caregiver, researcher and most importantly, the infertile couple (Table 1).

\section{Acknowledgements}

We are grateful to Eldrid Borgan for editing the manuscript. We also thank Pernille Frese for making the timeline figure.

\section{References}

1. Callaway E (2014) Reproductive medicine: The power of three.

2. Steptoe PC, Edwards RG (1978) Birth after the reimplantation of a human embryo. Lancet 2: 366 .

3. De Geyter C (2018) More than 8 million babies born from IVF since the world's first in 1978 [pressemelding]: European Society of Human Reproduction and Embryology.

4. Trounson A, Mohr L (1983) Human pregnancy following cryopreservation, thawing and transfer of an eight-cel embryo. Nature 305: 707-709.

5. Palermo G, Joris H, Devroey P, Van Steirteghem AC (1992) Pregnancies after intracytoplasmic injection of single spermatozoon into an oocyte. Lancet 340: 17-18.

6. Handyside $\mathrm{AH}$, Kontogianni $\mathrm{EH}$, Hardy $\mathrm{K}$, Winston RM (1990) Pregnancies from biopsied human preimplantation embryos sexed by $\mathrm{Y}$-specific DNA amplification. Nature 344: 768-770.

7. Donnez J, Dolmans MM, Demylle D, Jadoul P, Pirard C, et al. (2004) Livebirth after orthotopic transplantation of cryopreserved ovarian tissue. Lancet 364: 1405-1410.

8. Brannstrom M, Johannesson L, Bokstrom $\mathrm{H}$, Kvarnstrom $\mathrm{N}$, Molne J, et al. (2015) Livebirth after uterus transplantation. Lancet 385: 607-616.

9. Slama R, Hansen OK, Ducot B, Bohet A, Sorensen D, et al. (2012) Estimation of the frequency of involuntary infertility on a nation-wide basis. Hum Reprod 27: 1489-1498.

\section{Disadvantages}

Low success rates

Expensive Not universally permitted

Male offspring may be infertile Invasive Invasive
10. Boivin J, Bunting L, Collins JA, Nygren KG (2007) International estimates of infertility prevalence and treatment-seeking: potential need and demand for infertility medical care. Hum Reprod 22: 1506-1512.

11. Broekmans FJ, Knauff EA, te Velde ER, Macklon NS, Fauser BC (2007) Female reproductive ageing: current knowledge and future trends. Trends Endocrinol Metab 18: 58-65.

12. (2017) Causes of female infertility. Wolters Kluwer Health.

13. Barratt CLR, Bjorndahl L, De Jonge CJ, Lamb DJ, Osorio Martini F, et al. (2017) The diagnosis of male infertility: an analysis of the evidence to support the development of global WHO guidance-challenges and future research opportunities. Hum Reprod Update 23: 660-680.

14. Pincus G, Enzmann EV (1935) The Comparative Behavior of Mammalian Eggs in Vivo and in Vitro : I. The Activation of Ovarian Eggs. J Exp Med 62: 665-675.

15. Pincus G, Enzmann EV (1934) Can Mammalian Eggs Undergo Normal Development in Vitro? Proc Natl Acad Sci U S A 20: 121-122.

16. Menkin MF, Rock J (1948) In vitro fertilization and cleavage of human ovarian eggs. Am J Obstet Gynecol 55: 440-452.

17. Bedford JM, Chang MC (1962) Fertilization of rabbit ova in vitro. Nature 193: 808-809.

18. Edwards RG (1965) Maturation in vitro of human ovarian oocytes. Lancet 2: 926-929.

19. Steptoe A (2015) Biology: Changing the world--a tribute to Patrick Steptoe, Robert Edwards and Jean Purdy. Hum Fertil (Camb) 18: 232-233.

20. http://www.nobelprize.org/nobel_prizes/medicine/ laureates/2010/

21. Laingbuisson (2018) IVF-dynamic innovative and growing market in the uk.

22. Hanevik HI, Kahn JA, Bergh A, Eriksen E, Friberg UM, et al. (2012) Results after assisted reproduction at a public fertility clinic. Tidsskr Nor Laegeforen 132: 947-951.

23. Cohen J, Trounson A, Dawson K, Jones H, Hazekamp J, et al. (2005) The early days of IVF outside the UK. Hum Reprod Update 11: 439-459.

24. Leeton J (2004) The early history of IVF in Australia and its contribution to the world (1970-1990). Aust N Z J Obstet Gynaecol 44: 495-501.

25. https://www.nytimes.com/1981/12/29/science/testtube-baby-born-in-us-joining-successes-around-the. html?sec=health

26. Fleming R, Adam AH, Barlow DH, Black WP, MacNaughton MC, et al. (1982) A new systematic treatment for infertile women with abnormal hormone profiles. $\mathrm{Br} \mathrm{J}$ Obstet Gynaecol 89: 80-83.

27. Kwan I, Bhattacharya S, Kang A, Woolner A (2014) Monitoring of stimulated cycles in assisted reproduction (IVF and ICSI). Cochrane Database Syst Rev 8. 
28. Wikland M, Hamberger L (1984) Ultrasound as a diagnostic and operative tool for in vitro fertilization and embryo replacement (IVF/ER) programs. J In Vitro Fert Embryo Transf 1: 213-216.

29. Thurin A, Hausken J, Hillensjo T, Jablonowska B, Pinborg A, et al. (2004) Elective single-embryo transfer versus double-embryo transfer in in vitro fertilization. N Engl J Med 351: 2392-2402.

30. Trounson A, Leeton J, Besanko M, Wood C, Conti A (1983) Pregnancy established in an infertile patient after transfer of a donated embryo fertilised in vitro. Br Med J (Clin Res Ed) 286: 835-838.

31. Shahbazi MN, Jedrusik A, Vuoristo $S$, Recher G, Hupalowska A, et al. (2016) Self-organization of the human embryo in the absence of maternal tissues. Nat Cell Biol 18: $700-708$.

32. Faddy MJ, Gosden MD, Gosden RG (2018) A demographic projection of the contribution of assisted reproductive technologies to world population growth. Reprod Biomed Online 36: 455-458. 